Br Heart F 1982; 48: 485-92

\title{
Tricuspid atresia: analysis of coronary artery distribution and ventricular morphology
}

\author{
JOHN E DEANFIELD, ^ GIUSEPPE TOMMASINI,† ROBERT H ANDERSON, \\ FERGUS J MACARTNEY
}

From The Hospital for Sick Children, Great Ormond Street, and the Cardiothoracic Institute, Brompton Hospital, Fulham Road, London

SUMMARY There is still disagreement concerning the precise nature of the anterior ventricular chamber in "tricuspid atresia". Some argue that it is a right ventricle, while our own previous studies have suggested it is comparable to the outlet chamber seen in classical "single ventricle".

We have compared the morphology of the anterior ventricular chambers in 48 examples of tricuspid atresia (absent right atrioventricular connection), 24 hearts with double inlet to the left ventricular chamber, and 15 hearts with pulmonary atresia and intact ventricular septum. Since there is further disagreement concerning the nature of the coronary artery which delimits the posterior extent of the ventricular septum in these hearts, we analysed the position of this vessel relative to external reference points on the atrioventricular junction.

No significant difference was found with respect to the morphometry of hearts with tricuspid atresia (absent right atrioventricular connection) and those with double inlet. In both groups, however, significant differences were shown between hearts with ventriculoarterial concordance and discordance. Coronary artery disposition was the same in both groups and different from that found in hearts with pulmonary atresia and intact septum.

We conclude that the ventricular morphology is comparable in hearts with tricuspid atresia (absent right atrioventricular connection) and those with double inlet to a left ventricular chamber. The lesions are distinguishable by their atrioventricular connection which is nevertheless univentricular in both.

There is fundamental disagreement concerning the morphology of the commonest variant of tricuspid atresia that is pertinent to its clinical diagnosis. On the one hand, it has been suggested that hearts which clinicians call tricuspid atresia can, in morphological terms, be grouped along with pulmonary atresia and intact ventricular septum. ${ }^{1}$ The advocates of this approach, however, fail to specify the precise morphology of the atrioventricular junction which

\footnotetext{
„Present address: Cardiac Department, Hammersmith Hospital, Ducane Road, London W12 0HS.

†Present address: Divisione di Cardiochirurgia Infantile, Ospedale Civile, Massa, Italy.

FJM and RHA are supported by the British Heart Foundation and by the Vandervell and Joseph Levy Foundations, respectively.

Accepted for publication 22 June 1982
}

produces the atretic atrioventricular valve. ${ }^{2}$ In this respect, some echocardiographic investigators ${ }^{34}$ have interpreted the usual form of tricuspid atresia in terms of an imperforate membrane placed between the right atrium and the hypoplastic right ventricle. On the other hand, our experience ${ }^{56}$ and that of others, ${ }^{7}$ have suggested that classical tricuspid atresia is the result not of an imperforate membrane but of absence of the right atrioventricular connection. More recent echocardiographic experience has borne out this contention. ${ }^{89}$ These latter studies show that the morphology in these cases is more akin to that found in hearts with double inlet to a left ventricular chamber, hearts that are generally accepted to be "single ventricles" 1011 despite the fact that they possess two chambers within the ventricular mass. Still others ${ }^{12}$ who have recognised absence of the right 
atrioventricular connection in some cases of tricuspid atresia have argued that the ventricular morphology differs from that found in hearts with double inlet to a left ventricular chamber because of the coronary artery distribution. Their view is shared by Bharati and $\mathrm{Lev}^{2}$ but is contrary to our observations. ${ }^{13}$ The resolution of this controversy rests in the nature of the right ventricular chamber in the commonest type of tricuspid atresia and in the morphology of the coronary arteries which delineate it. We have therefore studied these features in a group of hearts having the typical morphology of tricuspid atresia and compared the results with those obtained from examination of the right ventricular chamber in "pulmonary atresia with intact septum" and the so-called outlet chamber in "single ventricle". 1011

\section{Methods}

Seventy-two hearts from the pathology collections of The Hospital for Sick Children, Great Ormond Street, and the Cardiothoracic Institute, Brompton Hospital, were reviewed using a standard procedure. Forty-eight hearts exemplified the commonest variant of the anomaly which clinicians generally term tricuspid atresia. These hearts had absence of the right atrioventricular connection, the left atrium connected to the left ventricle and possessed a rudimentary right ventricular chamber. Twenty-four hearts had double inlet to a main ventricular chamber of left ventricular morphology with a rudimentary right ventricular chamber (single ventricle). 1011 These were compared with a further series of 15 hearts with atrioventricular concordance and small morphologically right ventricular cavities (pulmonary atresia with intact ventricular septum).

The atrial situs, precise anatomy of the atrioventricular junction, and the connections and relations of the great arteries were noted. The chambers in the ventricular mass were examined to establish their position, morphology, and dimensions, taking particular note of the septal orientation. It was immediately evident that there were similarities between the rudimentary ventricular chambers in the hearts with absent right atrioventricular connection (tricuspid atresia) and in the double inlet group. A divergence was found between both these groups and the hypoplastic right ventricles in the pulmonary atresia group. To investigate the similarities further, in the first two groups, distances were measured first from the apex of the right ventricular chamber to the lower margin of the foramen communicating with the left ventricular chamber, secondly from the upper margin of this foramen to the arterial valve, and finally from the apex of the right ventricular chamber to the arterial valve. The dimension of the left ventricular chamber

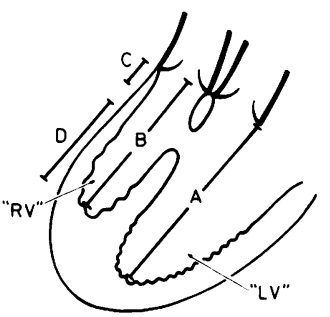

A : LV chamber length

B : RV chamber length

$C$ : interventricular communication to arterial valve length

D: interventricular communication to apex length

Fig. 1 Diagram to show measurements made on necropsy specimens.

was measured from its apex to the attachment of its arterial valve (Fig. 1). The coronary arteries and their branches were dissected and their pattern recorded. We were particularly concerned to establish if descending coronary arteries marked the site of the septum between the ventricular chambers. Where such delimiting branches were found, their site of descent was recorded relative to the landmarks of the atrioventricular junction, namely the obtuse and acute points of the junction and the crux, the latter being the point at which the atrial septum joined the atrioventricular junction. When a delimiting artery was found at the acute point, we then searched for any additional arteries descending at the crux or along the posterior margin of the ventricular mass, between the acute point and the crux.

The data were punched on to cards. Cross tabulation and analysis of variance were carried out using the Statistical packuge for the social sciences ${ }^{14}$ run on a CDC 6600 computer at the University of London Computer Centre.

\section{Results}

The sequential segmental features of the hearts with classical tricuspid atresia and double inlet to a chamber of left ventricular type are shown in Tables 1 to 3 . There was atrial situs solitus in all hearts except in five with double inlet, four of which had right atrial isomerism ${ }^{15}$ and one situs inversus.

\section{VENTRICULAR MORPHOLOGY}

All the hearts with pulmonary atresia with intact ventricular septum had morphologically right ventricular chambers which possessed inlet, trabecular, and outlet portions. In all hearts the outlet portion was blindending, the trabecular and inlet portions were hypoplastic to varying degrees, but the inlet part of the ventricular septum extended to the crux and was aligned with the atrial septum (Fig. 2). In contrast, the anterior ventricular chambers in the hearts with absent right atrioventricular connection and in those with double inlet lacked inlet portions. All possessed trabecular components that were unequivocally of right 
Table 1 Mode of atrioventricular connection

\begin{tabular}{|c|c|c|c|c|c|c|c|c|}
\hline & \multicolumn{8}{|c|}{ Atrioventricular valve } \\
\hline & Two valves & Common & $\begin{array}{l}\text { Imperforate } \\
\text { left }\end{array}$ & $\begin{array}{l}\text { Imperforate } \\
\text { right }\end{array}$ & $\begin{array}{l}\text { Straddling } \\
\text { left }\end{array}$ & $\begin{array}{l}\text { Straddling } \\
\text { right }\end{array}$ & $\begin{array}{l}\text { Absent } \\
\text { left }\end{array}$ & $\begin{array}{l}\text { Absent } \\
\text { right }\end{array}$ \\
\hline $\begin{array}{l}\text { Double inlet } \\
(\mathrm{n}=24)\end{array}$ & 19 & 5 & $1^{\star}$ & $1^{\star}$ & $2^{\star}$ & $4^{\star}$ & 0 & 0 \\
\hline $\begin{array}{l}\text { Tricuspid atresia } \\
(\mathrm{n}=48)\end{array}$ & 0 & 0 & 0 & 0 & $1 \dagger$ & 0 & 0 & 48 \\
\hline
\end{tabular}

Double inlet $=$ univentricular heart of left ventricular type with double inlet.

*The imperforate and straddling valves were present in hearts with two valves.

†The case with straddling left valve also had absent right atrioventricular connection.

Table 2 Ventriculoarterial connection

\begin{tabular}{llllll}
\hline & Concordant & Discordant & $\begin{array}{l}\text { Double outlet } \\
\text { LV chamber }\end{array}$ & $\begin{array}{l}\text { Double outlet } \\
\text { RV chamber }\end{array}$ & $\begin{array}{l}\text { Single outlet } \\
\text { with PA }\end{array}$ \\
\hline $\begin{array}{l}\text { Double inlet } \\
(\mathrm{n}=24)\end{array}$ & 3 & 13 & 4 & 1 & 3 \\
$\begin{array}{l}\text { Tricuspid atresia } \\
(\mathrm{n}=48)\end{array}$ & 29 & 15 & 1 & 1 & 2 \\
\hline
\end{tabular}

$\mathrm{LV}$, left ventricular; $\mathrm{RV}$, right ventricular; $\mathrm{PA}$, pulmonary atresia.

^All the cases with concordant ventriculoarterial connection had "normally related" great arteries.

Table 3 Position of right ventricular chamber relative to left ventricular chamber

\begin{tabular}{lllll}
\hline & $\begin{array}{l}\text { Left and } \\
\text { anterior }\end{array}$ & $\begin{array}{l}\text { Left and } \\
\text { posterior }\end{array}$ & $\begin{array}{l}\text { Right and } \\
\text { anterior }\end{array}$ & $\begin{array}{l}\text { Right and } \\
\text { posterior }\end{array}$ \\
\hline $\begin{array}{l}\text { Double inlet } \\
(\mathrm{n}=24)\end{array}$ & 11 & 0 & 10 & 3 \\
$\begin{array}{l}\text { Tricuspid atresia } \\
(\mathrm{n}=48)\end{array}$ & 2 & 0 & 46 & 0
\end{tabular}

*In these two cases, as in all the others with tricuspid atresia, the left atrium was connected to a morphologically left ventricular chamber.

ventricular type, and were separated from the left ventricular chamber by a septum that did not extend to the crux and that was grossly malaligned relative to the atrial septum (Fig. 3 and 4). The trabecular components of right ventricular morphology were hypoplastic to a varying degree and possessed none, one, or both outlet portions depending on the ventriculoarterial connection (see Tables 1 to 3).

Table 4 summarises the results of the measurements made on the right ventricular chambers in the absent right atrioventricular connection (tricuspid atresia) and in the double inlet (single ventricle) groups. Two way analysis of variance showed a significant effect of the ventriculoarterial connection both on the ratio between the lengths of the morphologically right and left ventricular chambers $(p<0.025)$ and the ratio of distances from the apex of the morphologically right ventricular chamber to the interventricular communication, and from the interventricular defect to the arterial valve $(p<0.005)$. Hearts with ventriculoarterial concordance had relatively longer right ventricular chambers (Fig. 4), with the interventricular communication relatively nearer the apex (Fig. 3). In contrast, the atrioventricular connection present did not significantly affect the morphologically right ventricular dimensions $(p=0.6$ and $0 \cdot 2$, respectively), nor were there any significant two way interactions.

\section{CORONARY ARTERY DISTRIBUTION}

The distribution of the coronary arteries in the hearts is shown in Table 5. In the majority of hearts studied, the morphologically right ventricular chamber was delimited by coronary arteries.

In $14(93 \%)$ of the hearts with pulmonary atresia with intact ventricular septum, the artery which delimited the posterior extent of the ventricular septum descended at the crux. In contrast, in the group of hearts with absent right atrioventricular connection (tricuspid atresia) and in those with double inlet atrioventricular connection, the artery delimiting the posterior extent of the septum descended at the acute margin of the ventricular mass, and not at the crux (Fig. 5). The delimiting coronary arteries met at the apex of the morphologically right ventricular chamber in 22 cases (46\%) with absent right atrioventricular connection and five cases $(21 \%)$ with double inlet. An additional artery descending from the crux was found in $\mathbf{3 6}$ of $\mathbf{4 8}$ hearts $(75 \%)$ with absent right atrioventricular connection and 19 of 24 hearts $(79 \%)$ with double inlet to a left ventricular chamber. Eleven of the 12 cases with absent right atrioventricular connection (tricuspid atresia) with no artery visible at the crux had between one and three parallel arteries descending from the 

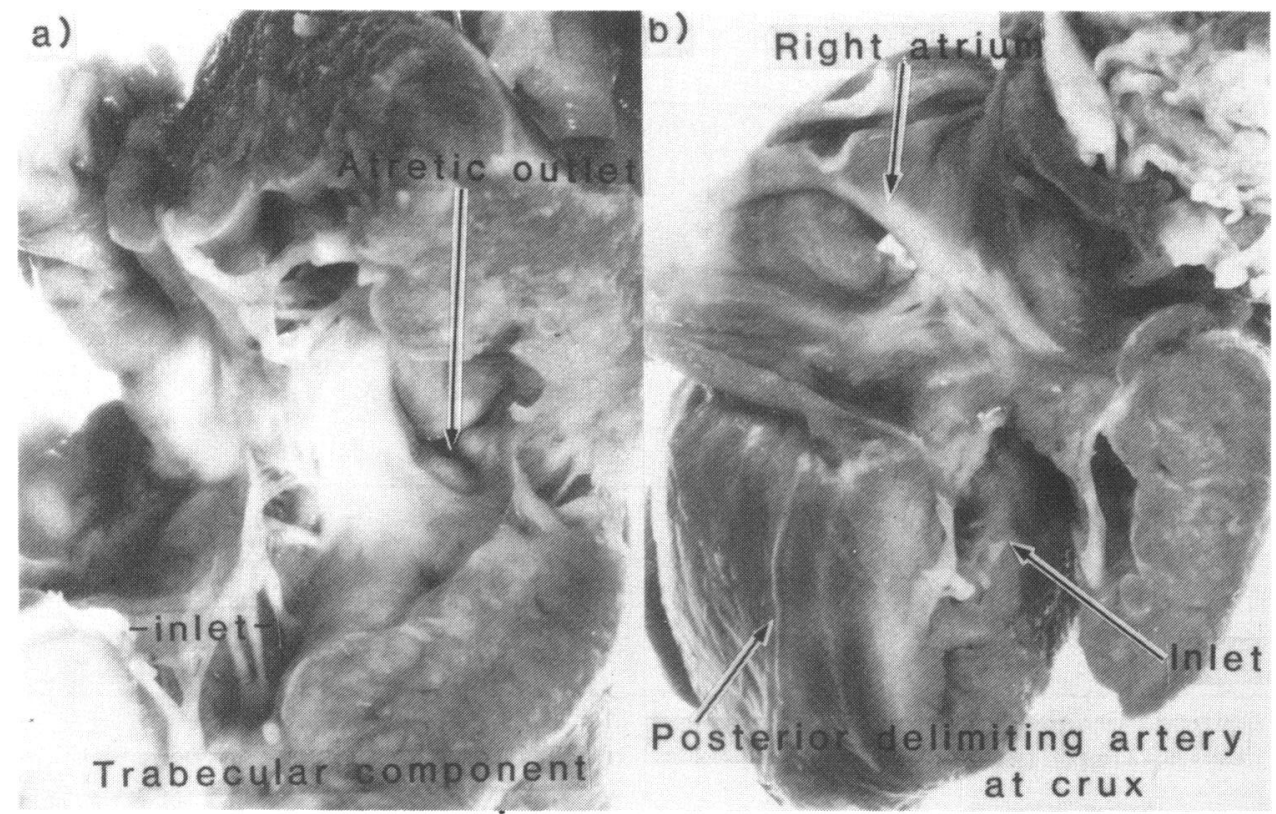

Fig. 2 Right ventricle in heart with pulmonary atresia and intact ventricular septum. (a) The interior of the right ventricle, viewed from its apex. The inlet portion of the right ventricle is delimited by the insertion of the tricuspid apparatus, and distal to the inlet portion is a trabecular component. There is infundibular atresia. (b) A view cut so as to show the relation of the interatrial septum to the atrioventricular groove; the posterior descending coronary artery is seen to originate normally from the crux of the heart.

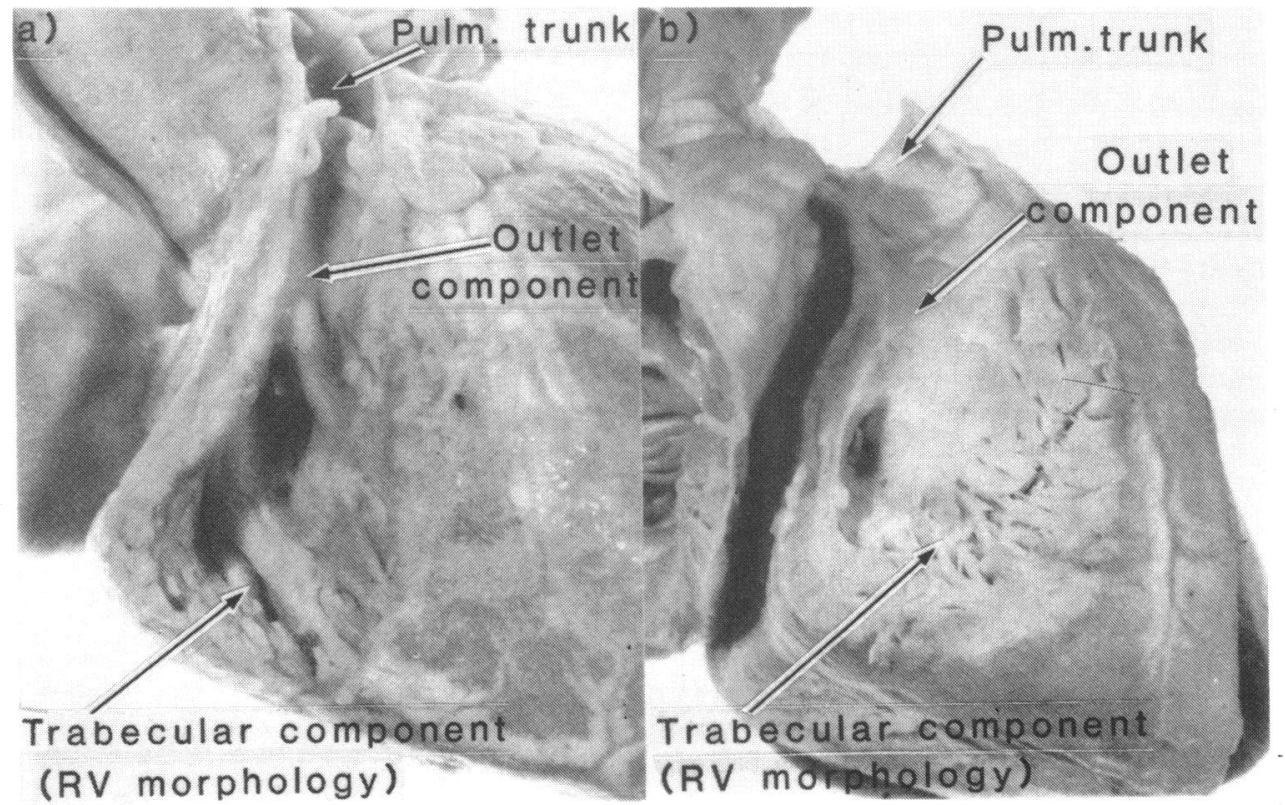

Fig. 3 Right ventricular chambers from two hearts in which that chamber gave origin to the pulmonary trunk. Note the remarkable similarity between the two chambers. (a) From a heart with a double inlet to the left ventricular chamber. (b) From a heart with absence of the right atrioventricular connection (classical tricuspid atresia). 
Table 4 Means and standard deviations of morphometric measures according to atrioventricular and arterial connection

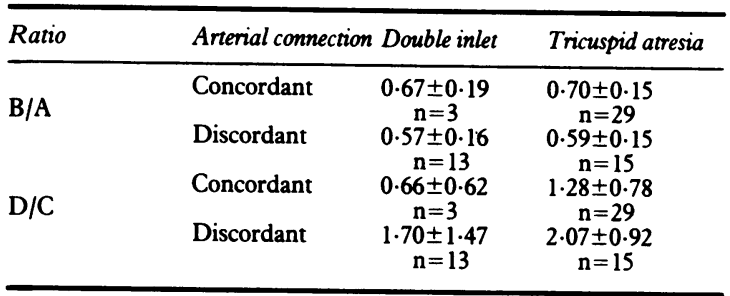

For interpretation of A, B, C, D, see Fig. 1 .

$\mathbf{n}=$ number in each subgroup.

Table 5 Coronary artery distribution

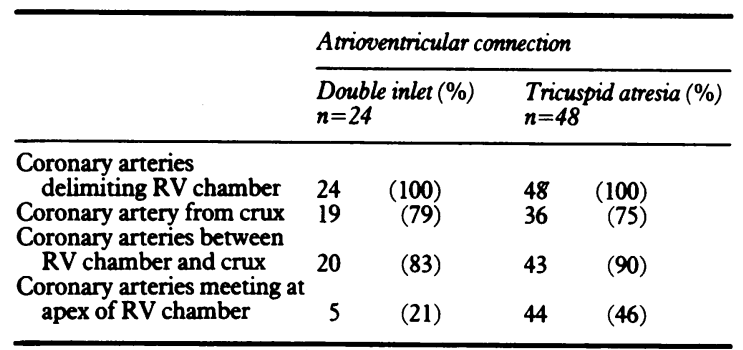

$\mathrm{RV}$, right ventricular. atrioventricular groove between the delimiting marginal coronary artery and the crux (Fig. 6). Such parallel branches were present in 43 cases $(90 \%)$ of the overall series with absent right atrioventricular connection (tricuspid atresia). Four of the five cases of double inlet with no crux artery had between one and seven parallel arteries between the rudimentary chamber and the crux: these arteries were present in $20(83 \%)$ of the overall series with double inlet.

\section{Discussion}

Our study has shown that the anterior ventricular chamber in the heart which most clinicians would simply term "tricuspid atresia" is indistinguishable from that found in the heart which many clinicians, again opting for simplicity, would term "single ventricle". The anterior chamber in these hearts, though having comparable trabecular pattern to the morphologically right ventricle in pulmonary atresia with intact ventricular septum, had an essential difference in its anatomy.

The morphologically right ventricle in pulmonary atresia has an inlet portion connected to the right atrium. The rudimentary right ventricular chambers in "tricuspid atresia" and "single ventricle" lack an inlet

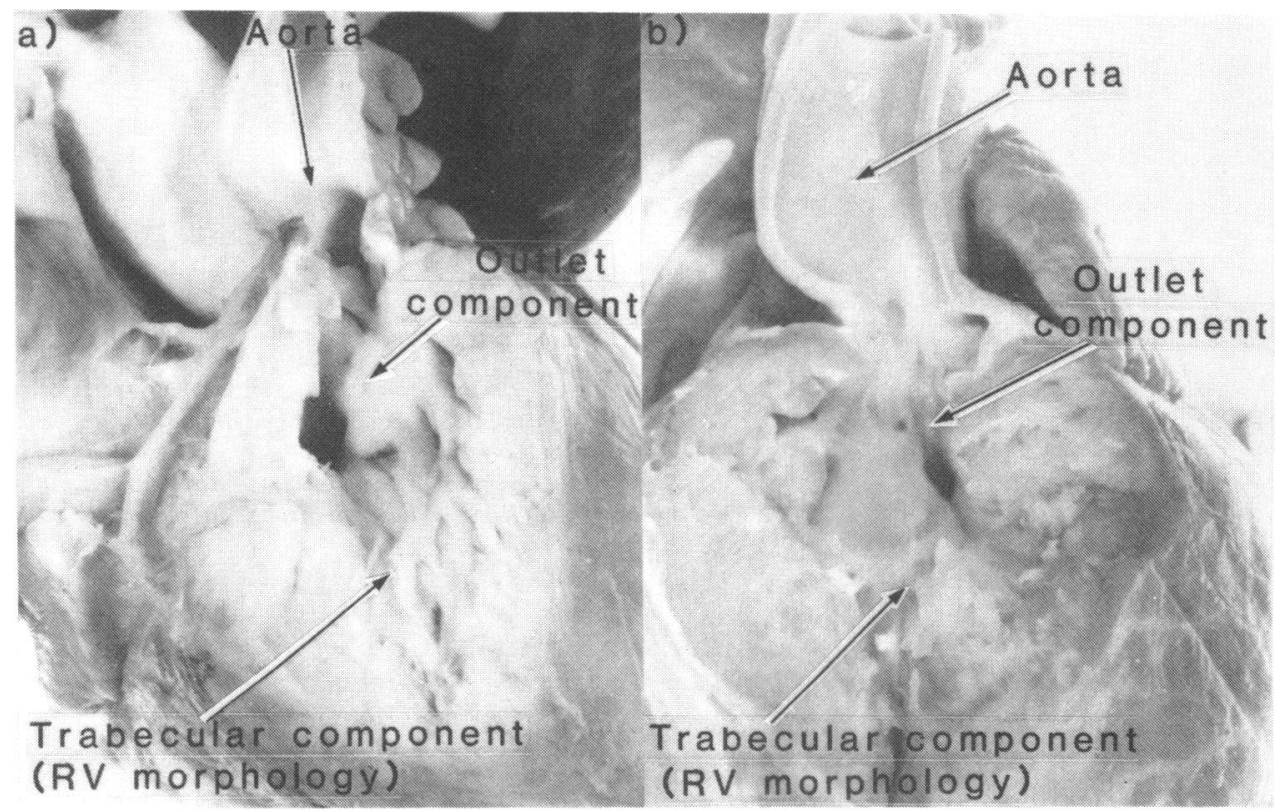

Fig. 4 Right ventricular chambers in hearts in which the right ventricle gave origin to the aorta. Note the remarkable similarity between the two. Note also that the overall length of the chamber is relatively less than in patients with normally connected great arteries (Fig. 3), and that the outlet foramen is relatively closer to the semilunar valve. (a) A heart with double inlet to the left ventricle. (b) From a heart in which there was absence of the right atrioventricular connection. 

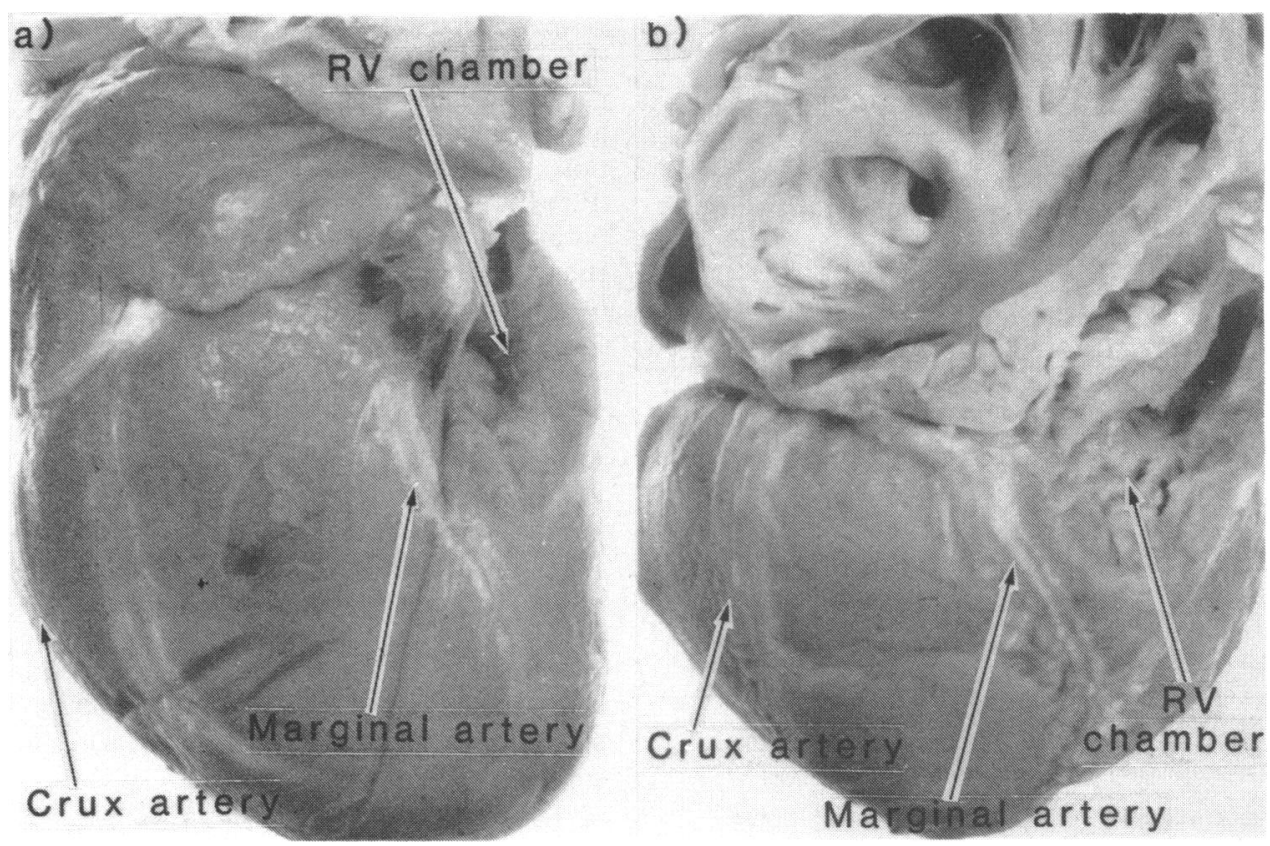

Fig. 5 Coronary artery morphology according to atrioventricular connection. (a) From a heart with double inlet to a left ventricle. Note the marginal antery delimiting the right ventricular chamber posteriorly, and the crux artery at the back of the heart. In between is a large parallel delimiting artery. (b) From a heart with absence of the right atrioventricular connection. Note that the right ventricular chamber is delimited by a marginal artery, and a quite separate coronary artery descends from the crux of the heart.

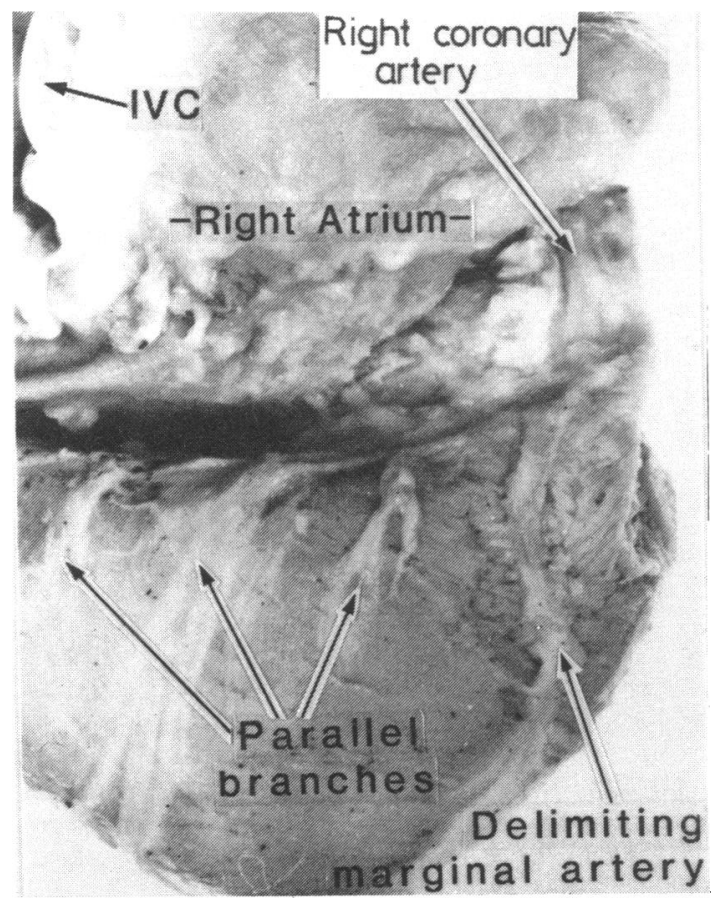

Fig. 6 The posterior aspect of the right atrioventricular junction in a heart with absence of the right atrioventricular connection. Note that there is not only a delimiting marginal artery posterior to the right ventricular chamber, but also numerous parallel branches between there and the crux of the heart, which is to the left of the inferior vena cava (IVC). 
portion and lack an atrioventricular connection. The anterior chambers in both these groups possess a trabecular component of unequivocally right ventricular pattern and their dimensions are statistically indistinguishable. As a corollary to these findings, the ventricular septum in pulmonary atresia extends to the crux whereas the septum in the other two groups does not. It is this septal morphology which determines the disposition of the delimiting coronary arteries. The posterior delimiting artery in pulmonary atresia descends at the crux whereas the posterior delimiting artery in the other two groups does not. Thus, in terms of ventricular morphology, hearts conforming to the typical variant of tricuspid atresia, which have absent right atrioventricular connection along with the left atrium connected to a left ventricular chamber, must be considered and interpreted along with double inlet to a left ventricular chamber (that is the classical single ventricle). They should not be grouped along with the pulmonary atresia and intact septum group, since these hearts have atrioventricular concordance and hypoplastic, but normally constituted, right ventricles.

These considerations are not merely of academic interest because logical and accurate classification of complex congenital heart lesions is necessary for correct diagnosis and treatment. The essential anatomical feature of echocardiographic interest in hearts with tricuspid atresia is that usually the septum does not extend to the crux. The morphologically right ventricular chamber, as in double inlet to a left ventricular chamber single ventricle), has no connection with the atrial chambers. ${ }^{89}$ The cavity of the right atrium may overlie the rudimentary right ventricle, and echocardiographically appear to be in potential communication with that of the right ventricular chamber. ${ }^{34}$ Only knowledge of the morphology, as here described, permits realisation 89 that the right atrium and the morphologically right ventricular chamber are, in fact, separated by atrioventricular sulcus tissue and not by an imperforate atretic valve (Fig. 7). Rare cases which, in clinical terms, would be diagnosed as having "tricuspid atresia", do exist with atrioventricular concordance and an imperforate right valve (Fig. 7), 51016 but they have fundamentally different morphology. They are indeed comparable to the hearts presently studied with pulmonary atresia and intact ventricular septum, since right and left atria are connected to right and left ventricles, respectively. In other words, they have a biventricular atrioventricular connection. In contrast, the hearts with absent right atrioventricular connection and double inlet are unified because only one ventricle in these hearts, the left ventricle, is connected to the atria. They have a univentricular atrioventricular connection.

It should not be construed from the above discussion that hearts with absent right atrioventricular connection (tricuspid atresia) have identical features to "single ventricle". As indicated, in the hearts most usually termed "single ventricle" both atria are connected to the left ventricular chamber whereas in the commonest variant of the hearts usually termed tricuspid atresia, only the left atrial chamber is connected to the left ventricular chamber. The significant point is that these differences can only be recognised when the left ventricular chamber is examined. A fundamental principle underlying definition of chambers in congenitally malformed hearts is that they can be recognisable in their own right (the "morphological method"). 17 We have shown that the anterior chambers in tricuspid atresia and in single ventricle cannot be distinguished in terms of their trabecular

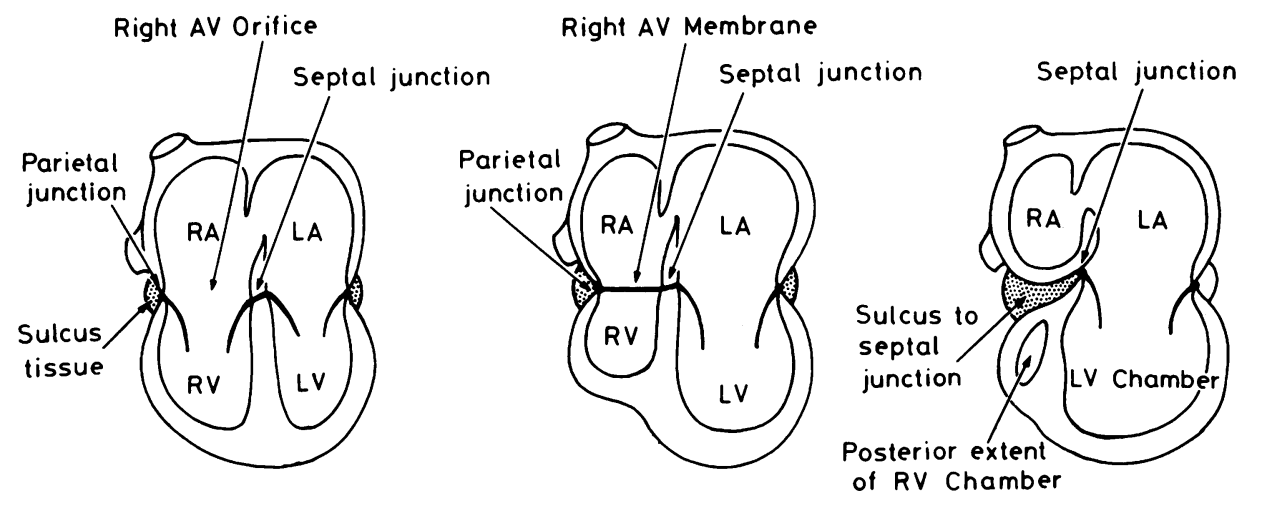

a) Normal Heart

b) Imperforate Right AV Valve

c) Classical Tricuspid Atresia

Fig. 7 Diagram illustrating the fundamental difference between the normal heart $(a), a$ heart with tricuspid atresia caused by imperforate tricuspid valve (b), and a heart with classical tricuspid atresia (c) resulting from absence of the right atrioventricular connection. 
components, both being of right ventricular pattern. The "morphological method" in this case points to their similarity. When differences did exist, they were related to the ventriculoarterial connection present. There was a recognisable difference between a right ventricular chamber supporting an aorta and one supporting a pulmonary trunk, but these differences applied both to hearts with absent right atrioventricular connection and those with double inlet. One difficulty in appreciating this comes from the fact that hearts with absent right atrioventricular connection are seen most frequently with ventriculoarterial concordance and hearts with double inlet usually have ventriculoarterial discordance. But when like is compared with like, that is absent right atrioventricular connection and double inlet with the same ventriculoarterial connections and relations, then the morphology of the right ventricular chamber is indistinguishable.

The anatomical features of diagnostic significance discussed above may well have been obscured previously by controversies concerning the "singleness" of the ventricular mass. ${ }^{25-7}$ There is no doubt that the majority of cases termed "single ventricle" possess two chambers within their ventricular mass. ${ }^{8918}$ In this respect "single ventricle" as a term is supported by habit rather than morphological accuracy. Habit will undoubtedly dictate that the term "single ventricle" will persist, as will "tricuspid atresia". It must therefore be appreciated that hearts of grossly diverse morphology are included within the term "tricuspid atresia". None the less, the greater majority of the hearts making up "tricuspid atresia" are indistinguishable from classical "single ventricle and outlet chamber" in terms of ventricular morphology and distinguished only by the atrioventricular connection. The atrioventricular connection, however, is truly univentricular in both these groups. It is this univentricular atrioventricular connection that distinguishes the commonest variant of tricuspid atresia from the rarer hearts with imperforate tricuspid valves and those others with pulmonary atresia and intact ventricular septum, which have a biventricular atrioventricular connection.

\section{References}

1 Bharati S, McAllister HA, Tatooles CJ, et al. Anatomic variations in underdeveloped right ventricle related to tricuspid atresia and stenosis. $\mathcal{F}$ Thorac Cardiovasc Surg 1976; 72: 383-400.

2 Bharati S, Lev, M. Tricuspid atresia (letter). $\mathcal{F}$ Thorac Cardiovasc Surg 1977; 74: 328-9.

3 Vitarelli A, Gallo P, D'Addio AP, Colarizi P, Colloridi V, Cheorghiade M. Valutazione dell' atresia della tricuspide mediante ecocardiografia. I Analisi morfologica. G Ital Cardiol 1981; 11: 321-9.

4 Koiwaya Y, Watanabe K, Orita Y, Nakamura M, Hirata T. Contrast two-dimensional echocardiography in diagnosis of tricuspid atresia. Am Heart $\mathcal{F}$ 1981; 101: 507-10.

5 Anderson RH, Wilkinson JL, Gerlis IM, Smith A, Becker AE. Atresia of the right atrioventricular orifice. $\mathrm{BrHeart} \mathcal{F}$ 1977; 39: 414-28.

6 Anderson RH, Becker AE, Macartney FJ, Shinebourne EA, Wilkinson JL, Tynan MJ. Is "tricuspid atresia" a univentricular heart. Pediatr Cardiol 1979; 1: 51-6.

7 Vlad P. Tricuspid atresia. In: Keith JD, Rowe RD, Vlad $P$, eds. Heart disease in infancy and childhood. 3rd ed. New York: Macmillan, 1978: 518-41.

8 Sutherland GR, Godman MJ, Anderson RH, Hunter S. The spectrum of atrioventricular valve atresia: a twodimensional echocardiographic/pathological correlation. In: Rijsterborgh H, ed. Echocardiology. The Hague: Martinus Nijhoff, 1981: 345-53.

9 Rigby $M L$, Anderson RH, Gibson D, Jones ODH, Joseph MC, Shinebourne EA. Two-dimensional echocardiographic categorisation of the univentricular heart. Br Heart f 1981; 46: 603-12.

10 Van Praagh R, Ongley PA, Swan HJC. Anatomic types of single or common ventricle in man: morphologic and geometric aspects of sixty necropsied cases. $\mathrm{Am} \mathcal{F}$ Cardiol 1964; 13: 367-86.

11 Lev M, Liberthson RR, Kirkpatrick JR, Eckner FAO, Arcilla RA. Single (primitive) ventricle. Circulation 1969; 39: 577-91.

12 Ando M, Satomi G, Takao A. Atresia of tricuspid or mitral orifice: anatomic spectrum and morphogenetic hypothesis. In: Van Praagh R, Takao A, eds. Etiology and morphogenesis of congenital heart disease. Mount Kisko, New York: Futura, 1980: 421-88.

13 Anderson RH, Shinebourne EA, Becker AE, Macartney FJ, Wilkinson JL, Tynan MJ. Tricuspid atresia and univentricular heart (letter). Pediatr Cardiol 1979; 1: 165.

14 Nie NH, Hull CH, Jenkins JG, Steinbrenner K, Bent DH. Statistical package for the social sciences. 2nd ed. New York: McGraw-Hill, 1975.

15 Macartney FJ, Zuberbuhler JR, Anderson RH. Morphological considerations pertaining to recognition of atrial isomerism. Consequences for sequential chamber localisation. Br Heart f 1980; 44: 657-67.

16 Rao PS, Jue KL, Isabel-Jones J, Ruttenberg HD. Ebstein's malformation of the tricuspid valve with atresia. Am f Cardiol 1973; 32: 1004-9.

17 Lev M. Pathologic diagnosis of positional variations in cardiac chambers in congenital heart disease. Lab Invest 1954; 3: 71-82.

18 Anderson RH, Tynan MJ, Freedom RM, et al. Ventricular morphology in the univentricular heart. Herz 1979; 4: 184-97.

Requests for reprints to Professor $\mathrm{R} H$ Anderson, Department of Paediatrics, Cardiothoracic Institute, Fulham Road, London SW36HP. 